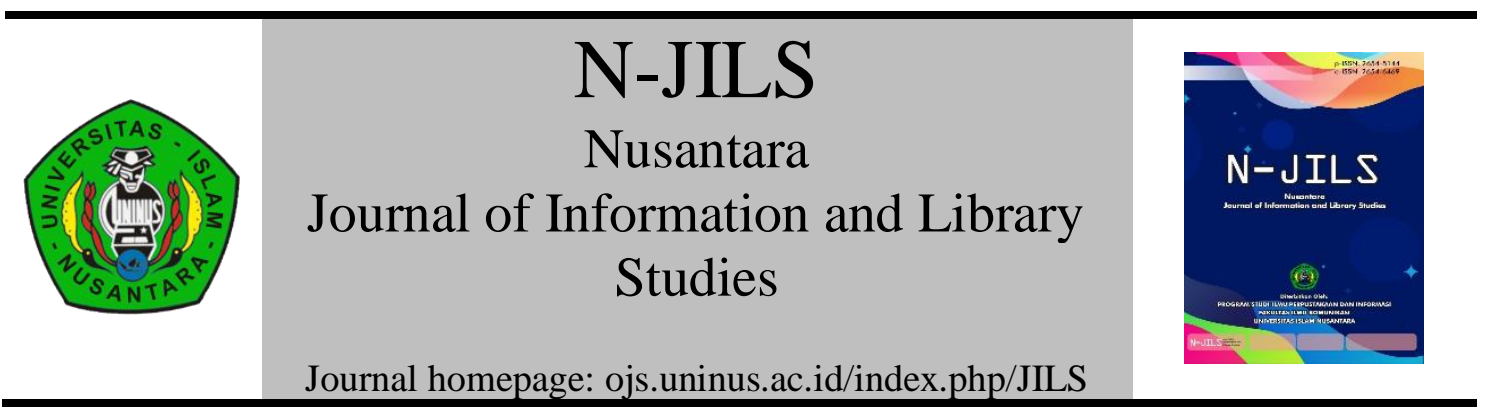

\title{
Manajamen Pengetahuan dan Pengaruhnya Terhadap Kinerja Tenaga Perpustakaan
}

\section{Knowledge Management and Its Impact On Library Performance}

\author{
Yunus Winoto*1, Dedi Irawan², Asep Saeful Rohman ${ }^{3}$ \\ 1,2,3 Universitas Padjadjaran \\ e-mail: *1yunuswinoto@gmail.com, ${ }^{2}$ dedirwn071@gmail.com, ${ }^{3}$ asep.saeful@unpad.ac.id
}

\begin{tabular}{|c|c|}
\hline ARTICLE INFO & ABSTRACT \\
\hline $\begin{array}{l}\text { Article history } \\
\text { Received [November, 2020] } \\
\text { Revised [November, 2020] } \\
\text { Accepted [December, 2020] } \\
\text { Available Online [December, 2020] }\end{array}$ & $\begin{array}{l}\text { This study aims to determine the effect of knowledge } \\
\text { management which includes aspects of knowledge creation, } \\
\text { knowledge sharing, and knowledge utilization on the } \\
\text { performance of library staff either partially or } \\
\text { simultaneously. The method used in this research uses a } \\
\text { quantitative approach with this type of explanatory survey } \\
\text { research. As for the so-called type of survey explanatory } \\
\text { research is research that does not only describe or describe } \\
\text { a phenomenon but also aims to provide an explanation of the } \\
\text { phenomenon. Meanwhile, the population in this } \\
\text { determination were employees of the Binus LKC Jakarta } \\
\text { library. With the sampling technique using a simple random } \\
\text { sample. Regarding the theory used in this study is the } \\
\text { knowledge-based view theory from Grant, while for } \\
\text { measuring knowledge management using the concept of } \\
\text { knowledge management from Shujahat and performance } \\
\text { measurement using the concept of performance from } \\
\text { Mangkunegara. The data collection technique was carried } \\
\text { out using a questionnaire distributed to Binus LKC } \\
\text { employees, interviews with library managers, observations } \\
\text { about library management activities at Binus LKC and } \\
\text { through library studies. Based on the research results, it } \\
\text { shows that knowledge management has a significant effect } \\
\text { on the performance of librarians by 68\%. Meanwhile, } \\
\text { partially, the aspects of knowledge creation and aspects of } \\
\text { knowledge sharing have a significant influence on the } \\
\text { performance of library staff. However, the knowledge } \\
\text { utilization aspect partially does not have a significant effect } \\
\text { on the performance of library staff. }\end{array}$ \\
\hline
\end{tabular}


Keyword: knowledge management; library staff; performance

\section{Kata kunci: manajemen pengetahuan; staf perpustakaan; kinerja}

\begin{abstract}
ABSTRAK
Penelitian ini bertujuan untuk mengetahui pengaruh knowledge management yang meliputi aspek knowledge creation, knowledge sharing, dan knowledge utilization terhadap kinerja tenaga perpustakaan baik secara parsial maupun simultan. Metode yang digunakan dalam penelitian ini menggunakan pendekatan kuantitatif dengan jenis penelitian eksplanatori survey. Adapun yang disebut dengan jenis penelitian eksplanatori survey adalah penelitian yang tidak hanya sekedar menggambarkan atau mendeskripsikan suatu fenomena namun juga bertujuan untuk memberikan penjelasan tentang fenomena tersebut. Sedangkan yang menjadi populasi dalam penetian ini adalah para karyawan perpustakan Binus LKC Jakarta. Dengan Teknik pengambilan sampelnya menggunakan jenis sampel acak sederhana. Mengenai teori yang digunakan dalam penelitian ini adalah teori knowledge based-view dari Grant sedangkan untuk pengukuran knowledge management menggunakan konsep knowledge management dari Shujahat dan serta pengukuran kinerja menggunakan konsep kinerja dari Mangkunegara. Teknik pengumpulan data dilakukan dengan menggunakan angket yang disebarkan pada para karyawan Binus LKC, wawancara dengan pengelola perpustakaan, observasi mengenai kegiatan penyelenggaraan perpustakaan di Binus LKC serta melalui studi kepustakaan. Berdasarkan hasil penelitian menunjukkan bahwa manajemen pengetahuan memiliki pengaruh yang signifikan pada kinerja tenaga perpustakaan sebesar $68 \%$. Sedangkan secara parsial aspek knowledge creation dan aspek knowledge sharing memiliki pengaruh yang signifikan terhadap kinerja tenaga perpustakaan. Namun untuk aspek knowledge utilization secara parsial tidak memiliki pengaruh signifikan terhadap kinerja tenaga perpustakaan.
\end{abstract}

(c) 2020 NJILS. All rights reserved.

\section{A. PENDAhULUAN}

Informasi yang telah diproses dalam otak manusia dapat dikatakan pengetahuan. Pengetahuan menjadi modal utama manusia dalam menjalankan kehidupannya. Pengetahuan tercipta ketika informasi menjadi dasar untuk bertindak seseorang atau intuisinya untuk mengambil sebuah tindakan. Informasi yang ada diproses oleh pikiran manusia, kemudian menimbulkan sebuah persepsi yang dapat disebut pengetahuan. Probst, Raub, Romhardt (2000), pengetahuan merupakan keseluruhan kognisi dan keterampilan individu untuk memecahkan sebuah permasalahan (Nawawi, 2012). Begitupun dalam sebuah organisasi, informasi tercipta dari aktivitas organisasi yang kemudian digunakan untuk mengambil sebuah keputusan yang penting bagi keberhasilan organisasi. 
Dalam sebuah organisasi, pengetahuan berasal dari individu yang terlibat dengan organisasi dan aktivitas organisasi yang menciptakan informasi dalam beragam bentuk. Pengetahuan merupakan entitas yang unik bagi sebuah organisasi. Keunikan ini membuat pengetahuan menjadi sebuah aset tak berwujud yang dapat meningkatkan daya saing. Menurut Berney (1991) dikatakan bahwa pengetahuan adalah merupakan sumber daya yang dapat mendukung keunggulan daya saing (keunggulan kompetitif) karena berharga, langka, sulit ditiru, dan sulit digantikan yang akan menciptakan sebuah keunggulan organisasi yang berkelanjutan. Keunggulan organisasi dapat dicapai jika kompetitor lain tidak dapat meniru strategi organisasi. Hal senada juga dikemukakan oleh Grant (2014) yang menyebutkan bahwa pengetahuan dalam organisasi menjadi pengerak aktivitas organisasi. Tanpa adanya pengetahuan, efektivitas aktivitas menjadi kacau. Seluruh produktivitas manusia tergantung pada pengetahuan dan seluruh mesin sebetulnya merupakan manifestasi dari pengetahuan.

Masih berbicara tentang pengetahuan Wibowo (2016) menyatakan pentingnya pengetahuan bagi keberlangsungan organisasi memunculkan sebuah sistem baru dalam mengelola pengetahuan yang disebut dengan manajemen pengetahuan (knowledge management). Sedangkan pendapat lain tentang pengetahuan juga dikemukakan Davenport dan Lawrence (2018) yang menyatakan bahwa knowledge management merupakan alat pembelajaran organisasi dimana organisasi dapat menggunakan pengetahuan untuk memperbaiki rutinitas kerja dan memodifikasi tujuan organisasi. Knowledge management dapat dipandang sebagai sebuah kapabilitas individu dalam mencipta, menyimpan, menyebarkan, dan mengelola pengetahuan (Davenport et al., 2008 dalam Raharso and Tjahjawati, 2016).

Binus University atau Universitas Binus (Bina Nusantara) sebagai salah satu perguruan tinggi swasta yang mengalami persaingan yang sangat ketat ditengah menjamurnya perguruan tinggi lain. Dalam menghadapi sebuah persaingan, Universitas Binus dituntut untut menghasilkan keunggulan bersaing agar dapat bertahan pada masa ini. Universitas Binus telah menerapkan knowledgde management dalam meningkatkan inovasi dan kinerja perusahaan. Hal ini ditandai dengan adanya Directorate of Knowledge Management and Inovations yang telah didirikan pada tahun 2013. Tugas utama unit ini adalah memimpin pembentukan pengetahuan perusahaan dan akademik, meningkatkan budaya dan semangat inovasi serta membantu organisasi dan unit kerja dalam mencapai indeks kinerja tinggi. Universitas Binus pada visinya yaitu "a world class university in pursuit of innovation”, menjadikan knowledge management dijadikan sebuah alat dalam membentuk inovasi agar mampu bersaing di dunia bisnis. 
Dalam memenuhi kebutuhan informasi dari civitas akademik, Universitas Binus memiliki perpustakaan. Dalam UU No. 43 tahun 2007 tentang perpustakaan, perpustakaan merupakan institusi pengelola koleksi karya tulis, karya cetak, dan/atau karya rekam secara profesional dengan sistem yang baku yang bertujuan untuk memenuhi kebutuhan pendidikan, penelitian, informasi, pelestarian, dan rekreasi pemustaka. Perpustakaan perguruan tinggi bertujuan untuk mencapai Tri Dharma Perguruan Tinggi yang berupa pembelajaran, penelitian dan pengabdian masyarakat dengan cara memilih, menghimpun, mengelola, merawat, dan melayankan sumber informasi kepada civitas akademiknya.

Perpustakaan di Universitas Binus lebih dikenal dengan Binus Library and Knowledge Center atau Binus LKC. Sesuai dengan visinya, Binus LKC berperan dalam pengembangan, penyediaan, dan penyebaran informasi melalui layanan yang dapat mendukung pembelajaran, penelitian, dan penciptaan pengetahuan. Selain itu, Binus LKC berfungsi sebagai media belajar bagi seluruh elemen Universitas Binus. Binus LKC terletak pada kampus anggrek sebagai pusat, Joseph Wibowo Center, dan kampus kijang, dan kampus lain seperti Bekasi, Bandung, dan Tangerang. Binus LKC terintergrasi antara satu dengan yang lain. Sivitas akademik Binus atau dikenal sebagai Binusian lebih mudah menikmati fasilitas perpustakaan untuk mendukung pembelajaran dan penciptaan pengetahuannya. Dalam meningkatkan layanannya, Binus LKC melakukan kolaborasi dengan unit kerja Universitas Binus lainnya dan perpustakaan lain untuk meningkatkan kualitas layanan perpustakaan. Peningkatkan layanan yang dilakukan oleh Binus LKC berbasis teknologi informasi dan komunikasi agar nyaman, cepat, dan tepat bagi pemustakanya. Binus LKC dilengkapi dengan situs yang dapat diakses http://library.binus.ac.id/.

Dalam teori knowledge based view, pengetahuan dapat mempengaruhi keberhasilan sebuah organisasi dalam menghadapi masalah dan menghasilkan keunggulan kompetitif. Agar pengetahuan memberikan dampak maksimal, organisasi harus dapat mengelola pengetahuan yang ada. Pengetahuan mampu mengerakkan organisasi sesuai dengan tujuan dengan maksimal. Kemampuan organisasi dalam mengelola pengetahuan digambarkan dalam konsep manajemen pengetahuan. Berkaitan dengan pengetahuan Grant (2014) menyatakan pengetahuan merupakan sumber penciptaan nilai organisasi. Nilai organisasi penting bagi organisasi sebagai pengerak individu mencapai sebuah tujuan organisasi. Nilai organisasi diwujudkan dalam budaya organisasi. Budaya organisasi merupakan cara-cara atau perilaku orang melakukan sesuatu dalam organisasi. Individu dalam organisasi digerakan atas sebuah nilai dan keyakinan. Ketika individu tersebut percaya dengan nilai organisasi, individu berperilaku atas pandangan sebuah nilai organisasi. Nilai memicu sebuah perilaku sehingga 
dapat berdampak pada kinerja. Sedangkan mengenai Kinerja menurut Mangkunegara (2010) Kinerja atau job performance merupakan hasil kerja secara kuantitas dan kualitas dalam waktu tertentu yang dicapai oleh seseorang dalam melaksanakan pekerjaannya sesuai tanggung jawab yang diberikan kepada individu.

Dengan adanya knowledge management, tenaga perpustakaan dapat memperoleh hingga menggunakan pengetahuan yang ada untuk menjalankan pekerjaan secara efektif dan mengatasi masalah pekerjaan yang akan berdampak pada kinerjanya. Agar mendapatkan manfaat tersebut, organisasi harus mengelola pengetahuan sebagai sebuah aset. Konsep pengelolaan pengetahuan disebut dengan knowledge management. Menurut Alavi Dan Leidner (2001) manajemen pengetahuan dapat dilihat dari dua dimensi yakni dimensi proses dan teknologi. Adapun yang dimaksud dengan proses manajemen pengetahuan adalah merupakan sebuah alur pengetahuan dan proses pengaplikasian keahlian dalam sebuah organisasi.

Berdasarkan latarbelakang tersebut peneliti tertarik untuk mengkaji tentang manajemen pengetahuan dan pengaruhnya terhadap kinerja tenaga perpustakaan Binus Library and Knowledge Center. Adapun tujuan dari penelitian ini adalah untuk mengetahui pengaruh secara parsial yakni aspek knowledge creation, knowledge sharing serta knowledge utilization terhadap kinerja tenaga perpustakaan Binus Library and Knowledge Center. Selain itu juga peneliti ingin mengetahui aspek knowledge creation, knowledge sharing, dan knowledge utilization secara bersama-sama berpengaruh terhadap kinerja tenaga Perpustakaan Binus Library and Knowledge Center. Penelitian sangat menarik dan cukup penting untuk dikaji karena dapat menjelaskan aspek-aspek dalam menajamen pengetahuan dalam perspektif proses yang berpengaruh terhadap kinerja tenaga perpustakaan.

\section{B. TINJAUAN PUSTAKA}

Dalam melakukan penyusunan penelitian, penulis melakukan kajian terhadap beberapa penelitian yang pernah dilakukan sebelumnya yang dianggap revelan dengan penelitian. Pengkajian penelitian ini untuk melihat ciri khas dari penelitian ini dan membantu penulis dalam menganalisa kajian tema penelitian ini. Berikut ini mengenai ulasan penelitian terdahulu terkait knowledge management dan kinerja pengawai atau sumber daya manusia:

Tabel 1. Review Penelitian Terdahulu

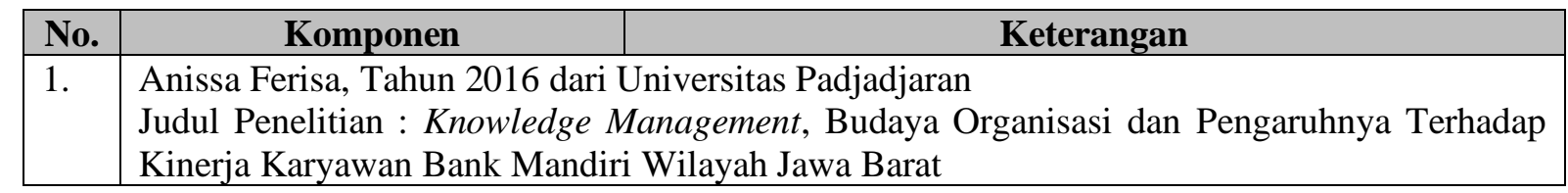




\begin{tabular}{|c|c|c|}
\hline & Tujuan Penelitian & $\begin{array}{l}\text { Untuk mengkaji dan menganalisis bentuk dan pengaruh knowledge } \\
\text { management terhadap kinerja karyawan Bank Mandiri Wilayah Jawa } \\
\text { Barat baik secara simultan maupun parsial. }\end{array}$ \\
\hline & Metode penelitian & Kuantitatif Eksplanatori. \\
\hline & Responden & 284 karyawan Bank Mandiri Wilayah Jabar \\
\hline & Teknik analisis data & Analisis jalur \\
\hline & Teori / Konsep & $\begin{array}{l}\text { Konsep Knowledge Management Liebowitc (1999), konsep budaya } \\
\text { organisasi dari Robbins (2013), dan konsep kinerja dari Gomes } \\
\text { (2012). }\end{array}$ \\
\hline & Hasil penelitian & $\begin{array}{l}\text { Penerapan knowledge management dan kinerja yang dilakukan oleh } \\
\text { Karyawan Bank Mandiri Wilayah Jawa Barat dikategorikan cukup } \\
\text { baik, sedangkan penilaian budaya organisasi karyawan dikategorikan } \\
\text { baik. Penerapan knowledge management dan budaya organisasi } \\
\text { terhadap kinerja karyawan Bank Mandiri Wilayah Jawab Barat } \\
\text { terdapat pengaruh secara simultan. Secara parsial, penerapan } \\
\text { knowledge management berpengaruh terhadap kinerja karyawan dan } \\
\text { budaya organisasi juga berpengaruh terhadap kinerja karyawan. }\end{array}$ \\
\hline 2. & \multicolumn{2}{|c|}{$\begin{array}{l}\text { Asti Nur Aryanti, tahun } 2017 \text { Dari Universitas Padjadjaran } \\
\text { Judul Penelitian : Penerapan Knowledge Management Terhadap Kinerja } \\
\text { Sumber Daya Manusia Dengan Kompetensi Sebagai Variabel Intervening: studi survey } \\
\text { Industri Kreatif Digital di Kota Bandung. }\end{array}$} \\
\hline & Tujuan Penelitian & $\begin{array}{l}\text { Untuk menguji pengaruh knowledge management terhadap kinerja } \\
\text { melalui kompetensi sebagai 226ariable intervening }\end{array}$ \\
\hline & Metode Penelitian & Kuantitatif dengan pendekataan survei \\
\hline & Responden & $\begin{array}{l}\text { sebanyak seluruh karyawan } 38 \text { perusahaan digital Bandung Digital } \\
\text { Valley yang menerapkan knowledge management. }\end{array}$ \\
\hline & Teknik analisis data & Analisis Partial Least Square (PLS) \\
\hline & Teori/konsep & $\begin{array}{l}\text { Konsep knowledge management dari Honeycutt (2005), konsep } \\
\text { kompetensi dari Spancer \& Spencer (2003), dan konsep kinerja SDM } \\
\text { dari Gomes (2003) }\end{array}$ \\
\hline & Hasil penelitian & $\begin{array}{l}\text { Terdapat pengaruh positif dan signifikan antar 226ariable, namun } \\
\text { pengaruh langsung antar 226ariable tersebut memiliki nilai lebih } \\
\text { kecil dibandingkan nilai pengaruh tidak langsung knowledge } \\
\text { management terhadap kinerja melalui 226ariable intervining yaitu } \\
\text { kompetensi }\end{array}$ \\
\hline 3. & \multicolumn{2}{|c|}{$\begin{array}{l}\text { Rifai Rajana Soleh, Tahun } 2019 \text { dari Universitas Padjadjaran } \\
\text { Judul Penelitian : Knowledge Management di Indonesia Port Corporation (IPC) Corporate } \\
\text { University" }\end{array}$} \\
\hline & Tujuan penelitian & $\begin{array}{l}\text { memberikan gambaran tentang konsep perencanaan dan pelaksanaan } \\
\text { knowledge management IPC Corporate University. }\end{array}$ \\
\hline & Metode penelitian & Studi grounded dengan pendekatan kualitatif \\
\hline & Teori / Konsep & Teori SECI dari Nonaka dan Takeuchi \\
\hline & Informan & $\begin{array}{l}\text { divisi knowledge management Indonesia Port Corporation (IPC) } \\
\text { Corporate University }\end{array}$ \\
\hline & Hasil penelitian & $\begin{array}{l}\text { Perencanaan knowledge management didasarkan pada tiga aspek } \\
\text { yaitu organizational learning, information technology, document } \\
\text { management yang nantinya akan mengadopsi visi, misi, dan tujuan } \\
\text { perusahaan. Bentuk knowledge management berbentuk program } \\
\text { kerja yang memiliki konten berfokus pada pengetahuan tasit dan } \\
\text { eksplisit. IPC Corporate University masih dalam membangun } \\
\text { budaya kerja yang berasaskan knowledge sharing. Hambatan dalam } \\
\text { implementasi knowledge management yaitu lemahnya kompleksitas } \\
\text { kerja, administrasi yang lama, mutase kerja dan belum adanya } \\
\text { regulasi. Strategi yang digunakan melakukan upaya skala prioritas }\end{array}$ \\
\hline
\end{tabular}




\begin{tabular}{|l|l|l|}
\hline & $\begin{array}{l}\text { program berdasarkan tingkat urgensinya serta pendekatan spiral } \\
\text { SECI dengan konsep pembelajaran sepanjang hayat }\end{array}$ \\
\hline
\end{tabular}

Sumber: Olahan Peneliti, 2019

Berdasarkan hasil kajian review penelitian terdahulu ada beberapa persamaan dan perbedaan dengan topik penelitian yang penulis lakukan. Adapun yang menjadi kesamaannya secara umum membahas tentang manajemen pengetahuan dan juga kinerja. Namun dalam penelitian yang penulis lakukan penelitian tentang manajemen pengetahuan dilihat dari aspek prosesnya yang meliputi knowledge creating, knowledge sharing serta knowledge utilization. Oleh karena demikian berdasarkan kajian penelitian terdahulu di atas dikaitkan dengan topik penelitian yang peneliti lakukan, berkesimpulan bahwa topik tentang manajemen pengetahun dengan fokus pada aspek proses yakni knowledge creating, knowledge sharing serta knowledge utilization, sangat layak untuk dilanjutkan untuk menjadi penelitian.

\section{Konsep Knowledge Management}

Definisi knowledge management sangatlah beragam bergantung pada faktor subjektif yang dipengaruhi oleh perbedaan implementasi knowledge management yang terjadi pada perusahaan. Menurut Tiwana (2000) dalam knowledge management adalah pengelolaan pengetahuan organisasi untuk menghasilkan keunggulan kompetitif dan untuk menciptakan nilai bisnis. Sedangkan dalam perspektif ilmu informasi dan perpustakaan, para ahli mendefinisikan knowledge management sebagai bagian dari ilmu informasi dan perpustakaan. Menurut IFLA (2018), manajemen pengetahuan (knowledge management), adalah sebuah proses penciptaan, penyimpanan, berbagi, pengaplikasiaan, dan pemustakaan kembali pengetahuan organisasi agar organisasi dapat mencapai tujuan dan sasarannya. Sedangkan Kebede (2010) mengatakan manajemen pengetahuan adalah merupakan sebuah proses dan alat untuk memaksimalan pengetahuan dalam pembuatan keputusan, pemecahan masalah, memfasilitasi inovasi dan kreativitas serta meraih keunggulan bersaing dalam beragam level (individu, grup, organisasi, negara, dan lain sebagainya).

Dalam konsep knowledge management, pengetahuan dibedakan menjadi dua jenis pengetahuan yaitu pengetahuan tasit dan pengetahuan eksplisit. Adapun pengetahuan tasit juga berupa subjektif, intuisi, dan firasat yang mengakar dari tindakan dan pengalaman-pengalaman individu. Pengetahuan ini bersifat khas, tersirat dan konteksnya sangat spesifik. Pengetahuan ini sangat sulit untuk dipindahkan dari masing-masing individu ke dalam individu lain karena sulit diartikulasikan dengan orang lain dengan hasil yang sama, dikembangkan dari pengalaman dan kegiatan secara langsung, dan dapat dibagikan melalui komunikasi interaktif, sehingga pengetahuan tasit dalam sebuah organisasi akan hilang ketika individu pemiliknya 
meninggalkan organisasi karena sepenuhnya tersimpan dalam diri manusia. Sedangkan pengetahuan adalah pengetahuan yang sudah disusun dalam bahasa yang sistematis atau dapat dikodifikasikan. Hal Senada juga dikemukakan Yusup (2010) yang mengatakan, bahwa pengetahuan eksplisit memiliki beberapa karaterisktik yaitu dapat dipindahkan dari penciptaan konteks asli, dapat diartikulasikan secara precis dan formal, terdokumentasi dengan baik, dan dapat dibagikan dengan menggunakan teknologi.

Kemudian mengenai proses knowledge management menurut Shujahat et al. (2017), terbagi menjadi 3, yakni: 1) Knowledge creation yakni suatu proses dalam menciptakan pengetahuan dalam menciptakan ide dan solusi atau dengan kata lain knowledge creation adalah sebuah proses dinamis dan interaktif dengan menghubungkan pengetahuan yang sudah ada maupun menghubungkan pengetahuan lama dengan pengetahuan yang baru untuk mengembangkan pengetahuan individu; 2) Knowledge sharing secara sederhana dapat diartikan sebagai transfer atau pengiriman pengetahuan maupun penyerapan pengetahuan; serta 3) Knowledge utilization dapat diartikan sebagai tahap aplikasi oleh individu secara bersama-sama untuk mencapai sebuah tujuan yang selanjutnya dapat disimpan di basis data organisasi seperti unit arsip, perpustakaan, dan sistem informasi. Pengaplikasian pengetahuan bergantung pada karakteristik individu yaitu kepribadian, preferensi mengenai cara belajar, cara penerimaan informasi dan cara organisasi membantu individu tersebut untuk menggunakan pengetahuan.

\section{Pengertian Kinerja}

Kinerja sering disebut dengan performa atau performance. Kinerja dapat diartikan sebagai hasil pekerjaan, namun juga sesuatu yang dikerjakan dan cara mengerjakannya sesuatu (Wibowo, 2016). Menurut Colquitt dkk. dalam Wibowo (2016), kinerja didefinisikan serangkaian perilaku yang memberikan kontribusi karyawan dalam penyelesaian tujuan organisasi. Dengan adanya kinerja, pekerja lebih mengetahui harapan yang ingin dicapainya dan menjadi fokus karena mengandung ukuran dan penilaian dalam mencapai tujuan (Cascio 2011 dalam Wibowo 2016). Gibson et. al., dalam Wibowo (2016) mengemukakan bahwa kinerja adalah hasil pekerjaan yang berkaitan dengan tujuan organisasi seperti efisiensi, kualitas, dan kriteria lain dari efektivitas organisasi. Adapun jika dilihat dari indikator, kinerja menurut Mangkunegara (2010), dapat dilihat dari aspek kuantitas kerja, kualitas kerja serta dari tanggung jawab, kerjasama serta aspek inisiatifnya. 


\section{METODE}

Penelitian ini mengunakan jenis pendekatan kuantitatif dengan jenis penelitian survey eksplanatori. Menurut Sugiyono (2014), penelitian eksplanatori merupakan penelitian yang bermasksud menjelaskan kedudukan variabel yang diteliti serta hubungan antara satu dengan yang lainnya. Sedangkan populasi dalam penelitian ini adalah para staf perpustakaan Binus Library and Knowledge Center Jakarta dengan teknik pengambilan sampel menggunakan sampel random sampling. Adapun jumlah sampel salam penelitian sebanyak 27 orang.

Kemudian untuk teknik pengumpulan datanya dilakukan melalui angket, observasi, wawancara serta melalui studi kepustakaan. Sedangkan untuk teknik analisis datanya dilakukan melalui teknik analisis deskriptif yakni dengan cara menyajikan dan memaparkan data secara deskriptif yang disajikan dalam bentuk tabel dan diagram untuk selanjutnya dianalisis. Sedangkan untuk pengujian hipotesisnya dilakukan dengan menggunakan analisis statistik inferensial. Pengertian statistika inferensial menurut Sugiyono (2014) statistika inferensial atau yang sering disebut statistika induktif adalah teknik statistik yang digunakan untuk menganalisa data sampel dan hasilnya diperlakukan untuk populasi.

\section{HASIL PENELITIAN DAN PEMBAHASAN}

Penelitian ini membahas tentang manajemen pengetahuan dan pengaruhnya terhadap kinerja tenaga perpustakaan di Binus Library and Knowledge Center Jakarta. Ada tiga aspek dalam manajemen pengetahuan yang akan duji pengerahuhnya terhadap kinerja tenaga perpustakaan yakni knowledge creation, knowledge sharing dan knowledge utilization. Untuk membahas hasil penelitian ini perlu dijelaskan secara ringkas gambaran perpustakaan Binus Library and Knowledge Center.

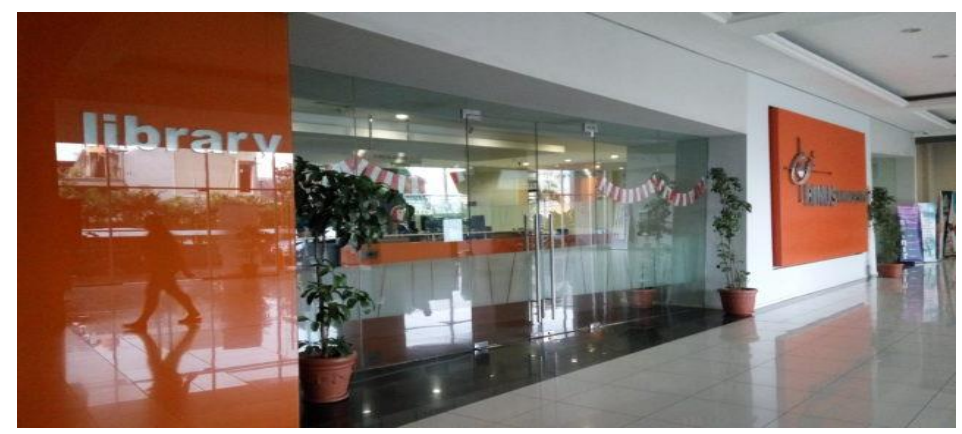

Gambar 1. Binus Library and Knowledge Center Sumber: Peneliti, 2019 


\section{Analisis Statistika Deskriptif}

Berdasarkan hasil pengolahan data data responden dapat digambarkan bahwa untuk data responden secara umum bahwa sebagian besar responden atau sekitar 59,3\% telah berkerja selama lebih dari 6 tahun dan berusia sekitar 31 tahun. Dilihat dari jenis kelaminnya sebagian besar berjenis kelamin laki-laki dengan pendidikan sebagian berpendidikan sarjana (S1) bidang ilmu perpustakaan. Mengenai banyaknya responden yang berpendidikan Sarjana ilmu perpustakaan juga dibenarkan Bapak Imam Budi sebagai kepala Perpustakaan BINUS LKJ Jakarta yang mengatakan bahwa,

"Sebagian besar karyawan kami berpendidikan bidang ilmu perpustakaan. Hal ini sejalan dengan kebutuhan kami terhadap tenaga yang memilki pengetahuan dan kompetensi bidang perpustakaan." (Imam Budi, Wawancara, Oktober, 2019).

Kemudian dari hasil pengolahan data penelitian dengan menggu-nakan analisis kategori dari variabel manajemen pengetahuan yang meliputi knowledge creation, knowledge sharing, knowledger utilization menun-jukan bahwa ketiga aspek tersebut berada pada kategori tinggi.

\section{Analisis Statistika Inferensial}

Penelitian ini mengunakan analisis inferensial untuk menghitung dan mengetahui hasil pengolahan data untuk melihat hubungan kedua variabel yaitu variabel $\mathrm{X}$ (Knowledge management) dan variabel Y (Kinerja) dan membuat kesimpulan dari penelitian ini. Dalam analisis statistif inferensial ini penelitian ini menggunakan regresi berganda. Adapun hasil dari analisis ini yaitu sebagai berikut.

Tabel 1. Hasil analisis regresi berganda

\begin{tabular}{|c|c|c|c|c|c|}
\hline \multirow[b]{2}{*}{ Model } & \multicolumn{2}{|c|}{$\begin{array}{c}\text { Unstandardized } \\
\text { Coefficients }\end{array}$} & \multirow{2}{*}{$\begin{array}{c}\text { Standardized } \\
\text { Coefficients } \\
\text { Beta }\end{array}$} & \multirow[b]{2}{*}{$\mathrm{t}$} & \multirow[b]{2}{*}{ Sig. } \\
\hline & $\mathrm{B}$ & Std. Error & & & \\
\hline 1 (Constant) & .105 & .465 & & .225 & .824 \\
\hline LN_X1 & .821 & .225 & .682 & 3.647 & .001 \\
\hline LN_X2 & .491 & .196 & .470 & 2.507 & .020 \\
\hline LN_X3 & -.279 & .231 & -.266 & -1.205 & .241 \\
\hline
\end{tabular}

a. Dependent Variable: LN_Y

Sumber: pengolahan data oleh SPSS, 2020

Berdasarkan tabel diatas, persamaan regresi Pengaruh Knowledge Management Terhadap Kinerja Tenaga Perpustakaan Binus LKC Jakarta sebagai berikut.

$$
\mathrm{Y}=0,105+0,821 \mathrm{X} 1+0,491 \mathrm{X} 2-0,279 \mathrm{X} 3
$$

Adapun arti dari koefisien regresi diatas yaitu memiliki nilai konstanta 0,105. Artinya apabila tidak dipengaruhi oleh variabel Knowledge Management (variabel X1 Knowledge 
Creation, variabel X2 Knowledge Sharing, dan variabel X3 Knowledge Utilization), maka variabel Kinerja akan meningkat sebesar 0,105. Nilai koefisien regresi b1, yaitu 0,821. Artinya apabila Knowledge Creation meningkat sebesar satu skor (satuan), maka Kinerja akan meningkat sebesar 0,821. Nilai koefisien regresi b2, yaitu 0,491. Artinya apabila Knowledge Sharing meningkat sebesar satu skor (satuan), maka Kinerja akan meningkat sebesar 0,491. Nilai koefisien regresi b3, yaitu 0,279. Artinya apabila Knowledge Utilization meningkat sebesar satu skor (satuan), maka kinerja akan menurun sebesar 0,279.

\section{Uji F (Simultan)}

Uji ini bertujuan untuk menguji pengaruh keseluruhan variabel $\mathrm{X}$ Knowledge Management (variabel X1, X2 dan X3) terhadap variabel Y Kinerja atau dapat disebut juga pengujian hipotesis mayor. Adapun hipotesisnya adalah:

Ho : Tidak ada pengaruh knowledge management terhadap kinerja Tenaga Perpustakaan Binus Library and Knowledge Center

Hi : Ada pengaruh knowledge management terhadap kinerja Tenaga Perpustakaan Binus Library and Knowledge Center

Adapun hasil pengujian ini sebagai berikut:

Tabel 2. Pengaruh antara Knowledge Management terhadap dengan Kinerja Tenaga Perpustakaan Binus LKC Jakarta

\begin{tabular}{|c|c|c|c|c|}
\hline Variabel & $\mathbf{F}_{\text {hitung }}$ & $\mathbf{F}_{\text {tabel }}$ & Nilai Sig. & Keputusan \\
\hline Knowledge Management $(\mathrm{X})$ & 18,455 & 2,781 & 0,000 & $\begin{array}{c}\text { Terdapat pengaruh } \\
\text { yang signifikan }\end{array}$ \\
\hline
\end{tabular}

Sumber: Pengolahan data, 2020

Berdasarkan tabel diatas diketahui bahwa nilai $F_{\text {hitung sebesar } 18,455 \text {. Harga kritis atau }}$ nilai $F_{\text {tabel }}$ ditemukan dengan cara melihat df pembilang dan df penyebut dengan taraf signifikasi $(\alpha)$ 0,05. df pembilang diperoleh 4 , sedangkan df penyebut diperoleh 22 . Dengan begitu, nilai $F_{\text {tabel }}$ dapat diketahui sebesar 2,781. Dari hasil tersebut, dapat diputuskan bahwa Ho ditolak dan Hi diterima karena nilai $F_{\text {hitung }}$ lebih besar dibanding nilai $F_{\text {tabel }}$. Dapat diputuskan bahwa variabel Knowledge Management memiliki pengaruh yang signifikan terhadap Kinerja Tenaga Perpustakaan Binus LKC Jakarta.

Hal ini menunjukkan bahwa Universitas Binus sudah memiliki sistem knowledge management yang dapat membantu karyawan seperti tenaga perpustakaan Binus LKC mencapai indeks kinerja tinggi sesuai dengan tujuan penerapan knowledge managementnya. Ini membuktikan juga bahwa sejalan dengan pendapat Tiwana (2000) bahwa knowledge management memiliki manfaat yaitu dapat meningkatkan kinerja individu. Pengetahuan 
menjadi salah satu faktor yang mempengaruhi kinerja (Sobirin, 2014). Pengelolaan pengetahuan yang baik dalam individu dapat meningkatkan kinerjanya karena individu dapat mencari dan menggunakan pengetahuannya dengan mudah.

\section{T (Parsial)}

Uji ini bertujuan untuk mengetahui pengaruh setiap sub variabel X (Knowledge Creation, Knowledge Sharing, dan Knowledge Utilization) secara masing masing terhadap variabel Y Kinerja.

\section{Uji T untuk Variabel X1 Knowledge Creation}

Adapun hipotesis dalam pengujian ini yaitu sebagai berikut.

Ho: Tidak ada pengaruh yang signifikan antara knowledge creation terhadap kinerja tenaga perpustakaan Binus Library and Knowledge Center

Hi: Ada pengaruh yang signifikan antara knowledge creation terhadap kinerja tenaga perpustakaan Binus Library and Knowledge Center

Adapun hasil pengujian ini sebagai berikut:

Tabel 3. Pengaruh antara Knowledge Creation dengan Kinerja Tenaga Perpustakaan Binus LKC Jakarta

\begin{tabular}{|c|c|c|c|c|}
\hline Variabel & $\mathbf{t}_{\text {hitung }}$ & $\mathbf{t}_{\text {tabel }}$ & Nilai Sig. & Keputusan \\
\hline $\begin{array}{c}\text { Knowledge Creation } \\
\text { (X1) }\end{array}$ & 3,647 & 2,060 & 0,001 & $\begin{array}{c}\text { terdapat pengaruh } \\
\text { yang signifikan }\end{array}$ \\
\hline
\end{tabular}

Sumber: Pengolahan data, 2020

Berdasarkan tabel diatas diketahui bahwa nilai thitung sebesar 3,647. Harga kritis atau nilai $t_{\text {tabel }}$ ditemukan dengan cara melihat df dengan taraf signifikasi $(\alpha) 0,05$, sehingga df penelitian ini adalah 25. Dengan begitu, nilai $t_{\text {tabel }}$ dapat diketahui sebesar 2,060. Dari hasil tersebut, dapat diputuskan bahwa Ho ditolak dan Hi diterima karena nilai $t_{\text {hitung }}$ lebih besar dibanding nilai $\mathrm{t}_{\text {tabel. }}$. Dapat diputuskan bahwa variabel Knowledge Creation memiliki pengaruh yang signifikan terhadap Kinerja Tenaga Perpustakaan Binus LKC Jakarta.

\section{Uji T untuk Variabel X2 Knowledge Sharing}

Adapun hipotesis dalam pengujian ini yaitu sebagai berikut.

Ho: Tidak ada pengaruh yang signifikan antara knowledge sharing terhadap kinerja tenaga perpustakaan Binus Library and Knowledge Center

Hi: Ada pengaruh yang signifikan antara knowledge sharing terhadap kinerja tenaga perpustakaan Binus Library and Knowledge Center

Adapun hasil pengujian ini sebagai berikut. 
Tabel 4. Pengaruh antara Knowledge Sharing dengan Kinerja Tenaga Perpustakaan Binus LKC Jakarta

\begin{tabular}{|c|c|c|c|c|}
\hline Variabel & $\mathbf{t}_{\text {hitung }}$ & $\mathbf{t}_{\text {tabel }}$ & Nilai Sig. & Keputusan \\
\hline $\begin{array}{c}\text { Knowledge Sharing } \\
\text { (X2) }\end{array}$ & 2,506 & 2,060 & 0.020 & $\begin{array}{c}\text { Terdapat pengaruh } \\
\text { signifikan }\end{array}$ \\
\hline
\end{tabular}

Sumber: Pengolahan data, 2020

Berdasarkan tabel diatas diketahui bahwa nilai thitung sebesar 2,506. Harga kritis atau nilai $t_{\text {tabel }}$ ditemukan dengan cara melihat df dengan taraf signifikasi $(\alpha) 0,05$, sehingga df penelitian ini adalah 25. Dengan begitu, nilai tabel dapat diketahui sebesar 2,060. Dari hasil tersebut, dapat diputuskan bahwa Ho ditolak dan Hi diterima karena nilai thitung lebih besar dibanding nilai $\mathrm{t}_{\text {tabel. }}$ Dapat diputuskan bahwa variabel Knowledge Sharing memiliki pengaruh yang signifikan terhadap Kinerja Tenaga Perpustakaan Binus LKC Jakarta.

\section{Uji T untuk Variabel X3 Knowledge Utilization}

Adapun hipotesis dalam pengujian ini yaitu sebagai berikut.

Ho: Tidak ada pengaruh yang signifikan antara knowledge utilization terhadap kinerja tenaga perpustakaan Binus Library and Knowledge Center

Hi: Ada hubungan yang signifikan antara knowledge utilization terhadap kinerja tenaga perpustakaan Binus Library and Knowledge Center

Adapun hasil pengujian ini sebagai berikut.

Tabel 5. Pengaruh antara Knowledge Utilization dengan Kinerja Tenaga Perpustakaan Binus LKC Jakarta

\begin{tabular}{|c|c|c|c|c|}
\hline Variabel & $\mathbf{t}_{\text {hitung }}$ & $\mathbf{t}_{\text {tabel }}$ & Nilai Sig. & Keputusan \\
\hline $\begin{array}{c}\text { Knowledge } \\
\text { Utilization (X3) }\end{array}$ & 1,205 & 2,060 & 0,241 & $\begin{array}{c}\text { Tidak terdapat pengaruh } \\
\text { signifikan }\end{array}$ \\
\hline
\end{tabular}

Sumber: (Pengolahan data 2020)

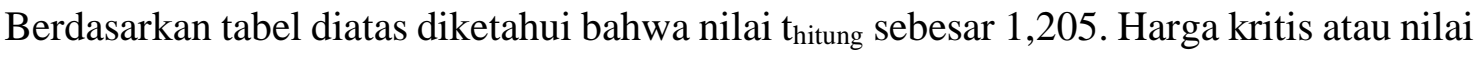
$t_{\text {tabel }}$ ditemukan dengan cara melihat df dengan taraf signifikasi $(\alpha) 0,05$, sehingga df penelitian ini adalah 25. Dengan begitu, nilai tabel dapat diketahui sebesar 2,060. Dari hasil tersebut, dapat diputuskan bahwa Ho diterima dan Hi ditolak karena nilai $t_{\text {hitung }}$ lebih kecil dibanding nilai $t_{\text {tabel }}$. Dapat diputuskan bahwa variabel Knowledge Utilization tidak memiliki pengaruh yang signifikan terhadap Kinerja Tenaga Perpustakaan Binus LKC Jakarta.

\section{Analisis Koefisien Determinasi}

Analisis koefisien determinasi bertujuan untuk melihat seberapa besar sumbangan pengaruh setiap variabel baik variabel $\mathrm{X}$ terhadap variabel $\mathrm{Y}$. adapun hasil perhitungannya sebagai berikut. 
Tabel 6. Hasil uji koefisien determinasi variabel Knowledge Management terhadap Kinerja Tenaga Perpustakaan Binus LKC Jakarta

\begin{tabular}{|l|l|l|l|l|}
\hline & & & & \\
Model & $\mathrm{R}$ & R Square & Adjusted R Square & Std. Error of the Estimate \\
\hline 1 & $.846^{\mathrm{a}}$ & .716 & .677 & .15275 \\
\hline
\end{tabular}

a. Predictors: (Constant), LN_X3, LN_X1, LN_X2

b. Dependent Variable: LN_Y

Sumber: pengolahan data oleh SPSS

Berdasarkan tabel diatas diketahui bahwa bahwa nilai Adjusted $R$ Square (koefisien determinasi) sebesar 0,677 yang memiliki arti bahwa Knowledge Management (Knowledge Creation, Knowledge Sharing, dan Knowledge Utilization secara bersama-sama) memiliki pengaruh sebesar $68 \%$ terhadap Kinerja tenaga perpustakaan, sedangkan sisanya sebesar $32 \%$ dipengaruhi oleh variabel lain. Maka dari itu, Knowledge Management memiliki kontribusi yang cukup besar terhadap Kinerja Tenaga Perpustakaan Binus LKC Jakarta.

\section{E. KESIMPULAN}

Berdasarkan hasil penelitian dapat disimpulkan bahwa knowledge creation memiliki pengaruh yang signifikan dan positif terhadap kinerja. Adapun indikator yang memiliki aktivitas yang sangat tinggi adalah information understanding. Mengenai aspek knowledge sharing diketahui memiliki pengaruh signifikan dan positif terhadap kinerja. Pengaruh antara keduanya adalah kuat. Arah hubungan keduanya positif sehingga peningkatan aktivitas knowledge sharing akan berdampak pada peningkatakan kinerja pada Tenaga Perpustakaan Binus LKC. Indikator yang memiliki aktivitas paling tinggi adalah knowledge donating. Sedangkan untuk aspek knowlede utilization tidak memiliki pengaruh yang signifikan terhadap kinerja. Indikator yang memiliki aktivitas yang paling tinggi adalah kemampuan mempraktikan pedoman kerja dan alur kerja. Namun demikian jika dilihat secara keseluruhan aspek knowledge creation, knowledge sharing, dan knowledge (knowledge management) secara simultan memiliki pengaruh terhadap kinerja tenaga perpustakaan Binus LKC Jakarta dimana pengaruh keduanya kuat Sedangkan mengenai hasil temuan dilapangan ada beberapa saran dalam penelitian diantaranya perlu adanya pemberian apresiasi atau intensif perlu dilakukan untuk tenaga perpustakaan yang idenya berhasil diterapkan pada aktivitas Binus LKC atau paling aktif dalam berbagi pengetahuan. Hal ini dapat meningkatakan aktivitas knowledge utilization. Pemberian apresiasi atau intensif dapat dilakukan dengan memberikan kesempatan dan dukungan terhadap ide, apresiasi secara lisan atau tertulis, atau pelatihan yang dapat mengembangkan idenya. 


\section{DAFTAR PUSTAKA}

Alavi, M And Leidner (2001) Knowledge manajemen and knowledge manajemen sistem : Conceps foundation and research issue. MS Quarterly (25) 107 -136, access on https ://dx.doi.019/10.2307/3250961.

Anggapraja, Indra Taruna. (2016). "Pengaruh penerapan knowledge management dan pengembangan sumber daya manusia terhadap kinerja karyawan PT Telkom Tbk.”. Jurnal Aplikasi Manajemen 14(1):140-46. Diakses pada https://doi.org/10.18202/jam23026332.14.1.15.

Armstrong, Michael. (2006). Performance management: Key strategies and pratica guidelines. London: Kogan Page Limited.

Aryanti, Asti Nur. (2017), Pengaruh penerapan knowledge management terhadap kinerja sumber daya manusia dengan kompetensi sebagai variabel intervening: Studi survey pada industri kreatif di Bandung. Universitas Padjadjaran.

Aziz, Afrizal. (2006). Pustakawan sebagai tenaga profesional di bidang perpustakaan, informasi dan dokumentasi. Jurnal Kepustakawanan dan Masyarakat Membaca. (1): 22.

Barney, Jay. (1991). Firm resources and sustained competitive advantage. Journal of Management. 17(1): 99120.

Basuki, Sulistyo. (1991). Pengantar ilmu perpustakaan. Jakarta: Gramedia Pustaka Utama.

Dalkir, Kimiz. (2005). Knowledge. Oxford: Elsevier.

Davenport, Thomas and Prusak Lawrence. (2008). Working knowledge : How Organization Manage What The Know. access from http ://www.acm.org/ubiquity/book/t.davenport_html.

Desouza, Kevin C., and Scott Paquette. (2011). Knowledge management: An Introduction. New York: NealSchuman Publisher.

Ferissa, Annisa. (2016). Penerapan knowledge management, budaya organisasi dan pengaruhnya terhadap kinerja karyawan bank mandiri wilayah jawa barat. Universitas Padjadjaran.

Ghozali, Imam. (2011). Aplikasi analisis multivariate dengan program SPSS. Semarang: Badan Penerbit Universitas Diponegoro.

Grant, Robert M. (1996). Toward a knowledge-based theory of the firm. Strategic Management Journal 17 (Winter Special Issue).

Grant, Robert M. (2014). Knowledge based view. In Wiley Encyclopedia of Management. John Wiley \& Sons. Aditama.

Kemendikbud. (2016). Kamus besar bahasa indonesia daring. Jakarta: Kemendikbud.

Kianto, Aino, Muhammad Shujahat, Saddam Hussain, Faisal Nawaz, and Murad Ali. (2018). The impact of knowledge management on knowledge worker productivity management. Baltic Journal of Management. access on https://doi.org/10.1108/BJM-12-2017-0404.

Krogh, Georg von, Kazuo Ichijo, and Ikujiro Nonaka. (2000). Enabling knowledge creation: How to unlock the mystery of tacit knowledge and release the power of innovation. Oxford: Oxford University Press.

Mangkunegara, A.A. Anwar Prabu. (2010). Evaluasi kinerja sumber daya manusia. Bandung: Refika Aditama.

Munir, Ningky Sasanti. (2010). Penerapan manajemen pengetahauan di perusahaan di indonesia. Jakarta: LIPI.

Nawawi, Ismail. (2012). Manajemen pengetahuan: Teori dan praktik dalam mewujudkan daya saing organisasi bisnis dan publik. Bogor: Ghalia Indonesia.

Nazim, Mohammad, and Bhaskar Mukherjee. (2016). Knowledge management in libraries: Concepts, Tools and Approaches. Cambridge: Chandos. 
Nonaka, Ikujiro, Ryoko Toyama, and Toru Hirata. (2008). Managing flow: A process theory of the knowledgebased firm. New York: Palgrave Macmillan.

Penrose, Edith. (1959). The theory of the growth of the firm. Oxford: Oxford University Press.

Prasetiawan, Imam Budi. (2020). Prapenelitian knowledge management dan kinerja tenaga perpustakaan.

Prijana, Yunus Winoto, and Andri Yanto. (2016). Metode penelitian kuantitatif ilmu perpustakaan dan informasi. Bandung: Unpad Press.

Priyono. (2008). Metode penelitian kuantitatif. Sidoarjo: Zifatama Publishing.

Qalyubi, Sihabuddin. (2007). Dasar-dasar ilmu perpustakaan dan informasi. Yogyakarta: UIN Sunan Kalijaga.

Raharso, Sri, and Sri Surjani Tjahjawati. (2016). Organisasi berbasis pengetahuan melalui knowledge sharing. Bandung: Alfabeta.

Santoso, Singgih. (2001). Buku latihan spss statistik parametrik. Jakarta: Elex Media Komputindo.

Shujahat, Muhammad, Maria José, Saddam Hussain, Faisal Nawaz, Minhong Wang, and Muhammad Umer. (2017). Translating the impact of knowledge management processes into knowledge-based innovation: The neglected and mediating role of knowledge-worker productivity. Journal of Business Research, no. October: 0-1. https://doi.org/10.1016/j.jbusres. 2017.11.001.

Sobirin, Achmad. (2014). Konsep dasar kinerja dan manajemen kinerja. In Manajemen Kinerja. Jakarta: Universitas Terbuka.

Soleh, Rifai Rajana. (2019). Knowledge management di Indonesia Port Corporation (IPC) Corporate University. Universitas Padjadjaran.

Sugiyono. (2007). Statistika untuk penelitian. Bandung: Alfabeta.

. (2011). Metode Penelitian Kombinasi. Bandung: Alfabeta.

. (2014). Metode penelitian kuantitatif kualitatif dan R\&D. Bandung: Alfabeta.

Suharyanto. (2014). Glosarium istilah perpustakaan. Pare: FAM Publishing.

Sutarno, NS. (2003). Perpustakaan dan masyarakat. Jakarta: Yayasan Obor Indonesia.

Tiwana, Amrit. (2000). The knowledge management toolkit: Practical techniques for building a knowledge management system. Prentice Hall: Upper Saddle River.

Wibowo. (2016). Manajemen Kinerja. Depok: Raja Grafindo.

Yusuf, Pawit M. (2012). Perspektif manajemen pengetahuan, informasi, komunikasi, pendidikan dan perpustakaan. Jakarta: Rajawali Press.

Zack, Michael H. (1991). Developing a knowledge strategy. California Management Review. 41 (3).

Zargar, Ehsan, and Masoomeh Rezaee. (2013). The study of knowledge management effect on performance rate of employees. European Online Journal of Natural and Social Sciences. 2 (3): 3061-66. 